\title{
CARBOHYDRATE METABOLISM IN THE COELIAC SYNDROME
}

\author{
BY \\ J. L. EMERY, M.B., Ch.B., D.C.H. \\ (From the Department of Pathology, University of Bristol)
}

The coeliac sydrome presents one of the most obscure yet fascinating problems of childhood. Recently interest has centred around the possible causes of this disorder; but, after known causes have been eliminated, the majority of cases are classed as post-infective or idiopathic. Change in fat metabolism is the most obvious characteristic of the syndrome, but it is by no means certain in which system the primary disorder lies. The recent work of Andersen (1945) suggests that fat analysis will soon be placed on a more accurate basis. Meanwhile our knowledge of the disorder itself does not greatly advance, and we are confronted with a starvation syndrome in which it is orthodox treatment virtually to starve the patient of fat and carbohydrate.

Investigations involving respiratory exchanges and heat production are extremely difficult to carry out in children, particularly in the age groups showing the syndrome in its most severe form. Fleming and Hutchison (1924) carried out their investigations on marasmic children at rest after feeding. Thaysen $(1929,1935)$, maintaining that the coeliac state is juvenile sprue, overcame the difficulty by investigating cases of adult non-tropical sprue, and also one child aged eleven. He showed that the ingestion of glucose in sprue produced a marked rise in the respiratory quotient, associated with a flat oral glucose-tolerance curve, and concluded that glucose is absorbed normally and utilized very rapidly in these cases. There has since been a series of papers (Crawford, 1939; Badenoch and Morris, 1936; Parsons, 1932; Ross and Tonks, 1938) in which the conclusion is directly opposite, i.e. that there is in the coeliac syndrome a defective absorption of glucose. The latter view appears now to be generally accepted. These investigations, however, show several inconsistencies. Thus, Ross and Tonks (1938) describe a diminished sensitivity to insulin, while Badenoch and Morris (1936) show an increased sensitivity to the same dose. Ross and
Tonks find also a reduced intravenous glucose tolerance, while Crawford (1939) describes it as normal. Furthermore, dosage has often not been directly related to body weight. In-view of the apparent contradiction in these observations and conclusions, it was considered that a reinvestigation of the problem would be of value.

\section{Selection of Cases}

The material consisted of thirteen cases. In all, the onset was after weaning. All showed wasting, hypotonia, deflated buttocks, distended abdomen, steatorrhoea, and fat intolerance; also stunting of growth, hypochromic anaemia, capricious appetite and bowel action, and a tendency to wide variation in day-to-day body weight. There was no frank or radiological rickets. Duodenal intubation for the detection of pancreatic insufficiency could be performed only in three cases, and gave normal trypsin levels (using the technique of Andersen and Early, 1942). No case was included unless it showed a flat oral glucose-tolerance curve. (Note: following the observations of Thaysen (1929), Svensgaard (1931), and MacLean and Sullivan (1929), considerable interest in the low blood-sugar curve in sprue and in the 'coeliac' syndrome has led to this finding becoming one of the diagnostic criteria of these disorders. A low curve is considered to be one showing a rise in blood sugar less than $40 \mathrm{mg}$. per $100 \mathrm{c.cm}$. of blood above fasting level, where the intervals of blood sampling are fifteen minutes or less). Details of the cases are included in fig. 1 .

Controls. Control cases were of necessity convalescents. The older children were convalescent cases of erythema nodosum; younger children were healthy ' lodgers.'

Scope of present investigation. Using carefully regulated dosage, the investigations on which most of the theories have been based have been repeated, i.e. oral glucose tolerance, intravenous glucose tolerance, and intravenous insulin tolerance. Following this, the same dose of glucose which produced a flat sugar curve was given orally in combination 
with insulin and adrenaline, in such a way as to throw into relief any absorption or lack of absorption of glucose. Other tests concerned the underlying state of carbohydrate metabolism.

Methods of investigation. Dosage in all cases was carefully related to the actual body weight. In order to minimize variations in the general condition, the various tests were carried out on each patient as far as possible on succeeding days. The children were starved for four hours before each test; usually they had breakfast at 6.30 a.m., the test starting about 10.30 a.m. Meals missed during the morning were made up in the afternoon and evening. Rudeshill and Henderson (1941) observed that, in children, the blood-sugar level three and a half hours after a meal may be substituted for the fasting blood-sugar level. Acting on this observation, and so that as little break in the daily routine as possible might be required, the four-hour fasting period was taken.

Blood was taken from the heel or great toe direct into a $0.2 \mathrm{c} . \mathrm{cm}$. unoxalated Ostwald pipette. The method of sugar estimation was that of Folin and Wu, using a Kleet colorimeter. All manipulations of dosage, blood-taking, and estimation were carried out personally. In the curves reported, the resting sugar level is quoted as one figure; in most cases this denotes the mean of two samples taken in immediate succession. The difference in these two readings was usually $2 \mathrm{mg}$. per $100 \mathrm{c.cm}$. of blood or less, rarely as much as $5 \mathrm{mg}$. The oral glucose tolerance test was always carried out first, and simple insulin tolerance preceded the other tests involving the use of insulin. Daily variation in response could be allowed for only by varying the order of the tests, which, except for those previously mentioned, were performed in a haphazard order. It is thought that the uniformity of the response obtained is sufficient to prove the points mentioned at the end of each section.

\section{Technical Details and Comments on Tests}

Oral glucose tolerance. Glucose was given in the child's ordinary feeding cup, with about $60 \mathrm{c.cm}$. of water in the dosage of $1 \mathrm{~g}$. per $\mathrm{kg}$. of actual body weight. After this had been drunk, the cup was again partly filled with water and presented to the child to satisfy its thirst; $100 \mathrm{c} . \mathrm{cm}$. in all was allowed, and no subsequent fluid was given. All the children took the glucose readily, and no retching or vomiting occurred.

Intravenous insulin tolerance. This test consisted in the intravenous administration of 0.1 units of soluble insulin per $\mathrm{kg}$. of actual body weight, and in the noting of the blood-sugar level for at least two hours afterwards. Crawford (1939) reports the response to insulin as normal, but her observations were carried out over one hour only, and an analysis of her results shows the blood-sugar level to be falling at the end of an hour (her cases
3 and 5). Badenoch and Morris (1936), using a subcutaneous dose of insulin (4 units for all ages), showed a greater fall in blood sugar than normal, while Ross (1938), using the same dose intravenously, showed a depression smaller than normal. The test measures two distinct process: (a) the sensitivity of the blood-sugar level to insulin, and (b) the reaction of the body to a lowered blood glucose.

Intravenous insulin followed by oral glucose. The observation that the blood sugar remains low after the administration of insulin in 'coeliacs, suggested that the reaction be used to produce a sensitized state for the administration of oral glucose. The same dose of glucose was given as in the oral glucose-tolerance test, but at a time when the blood sugar was low and unlikely to rise spontaneously to normal (as judged by a previous curve on the patient).

Adrenaline after insulin. The response to adrenaline during prolonged hypoglycaemia due to insulin has been used as a test of pituitary function (Fraser et al., 1941). The dosage used by these observers was employed in the present series-i.e. $0-001 \mathrm{mg}$. per kg. of body weight intramuscularly. They consider that a response to adrenaline at the 120-minute period is indicative of a lack of hypoglycaemia-sensitivity, due to a failure of the response mechanism centred in the pituitary.

Adrenaline response at normal fasting level. The standard dose of adrenaline related to body weight was given intramuscularly (deltoid).

Oral glucose with intramuscular adrenaline. This test consisted essentially of combining the oral glucose test with the adrenaline test. The adrenaline was injected at the same time as the glucose (the same dose as was used in the previous tolerance test) was taken by mouth.

Intravenous glucose tolerance. The technique of this test - as regards dosage of glucose, interval of testing, and method of administration-varies with different observers. Ross, whose findings conflict with most others, cuts down on a vein-considering that this disturbs the child less than direct venepuncture. In the present cases, after the fasting samples of blood from the heel had been taken, $0.5 \mathrm{~g}$. of dextrose per $\mathrm{kg}$. of body weight in the form of a 25 per cent. solution in normal saline, was injected directly into a vein with a large syringe. Needle and vein were then washed through with a further $2 \mathrm{c.cm}$. of saline from a second syringe. The time taken over the injection was usually one minute, and always under two. The first blood specimen was then taken immediately; the subsequent intervals corresponded approximately with those used by Ross.

Method of charting. In order to make the diagrams clear, the curves (except in fig. 8) are shown in mg. per $100 \mathrm{c.cm}$. of blood, rising or falling from the resting blood-sugar level. The key to the cases is tabulated in fig. 1, and as it applies to all the charts it is not repeated. 


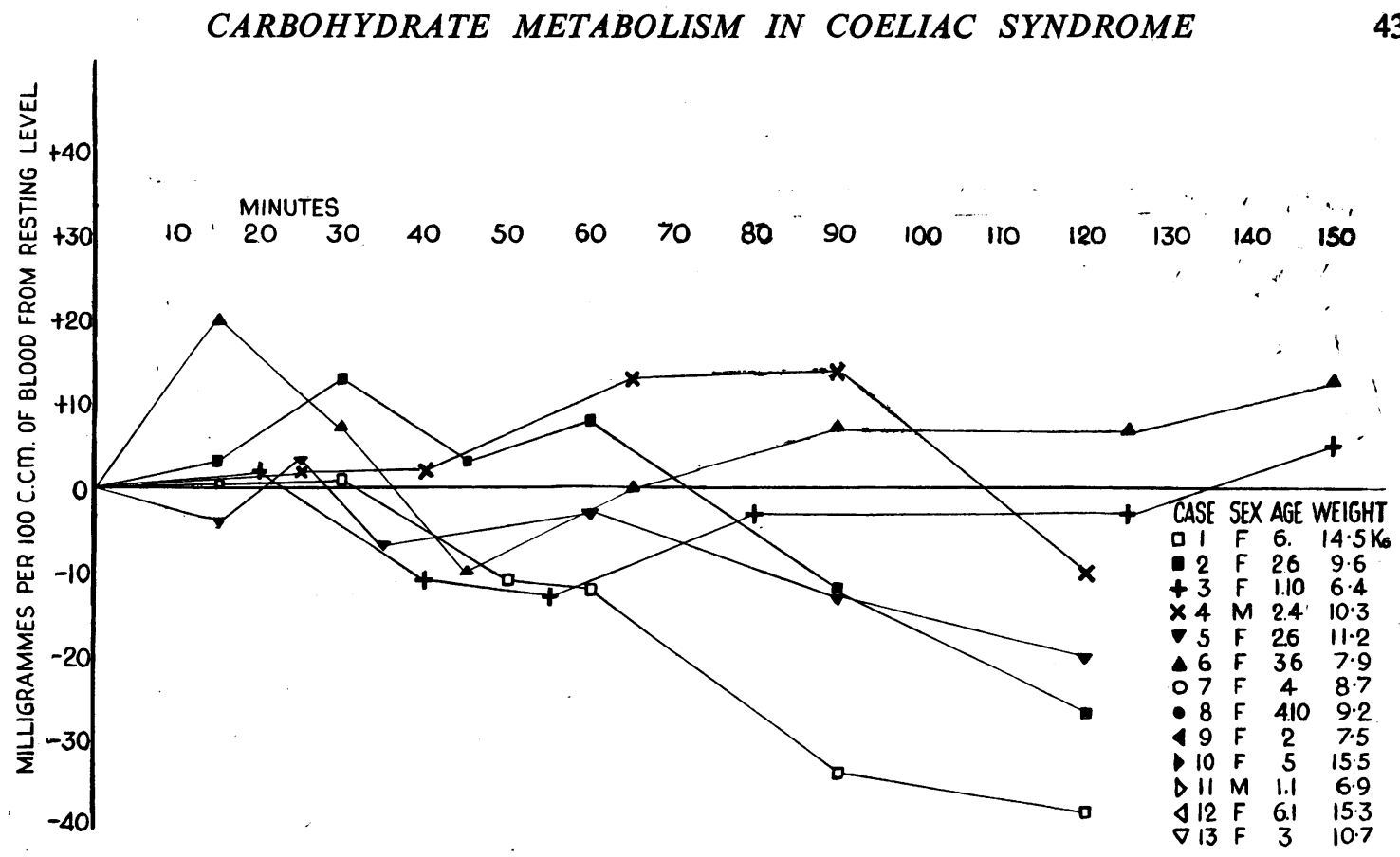

Fig. 1.-Oral glucose tolerance (cases 1 to 6).

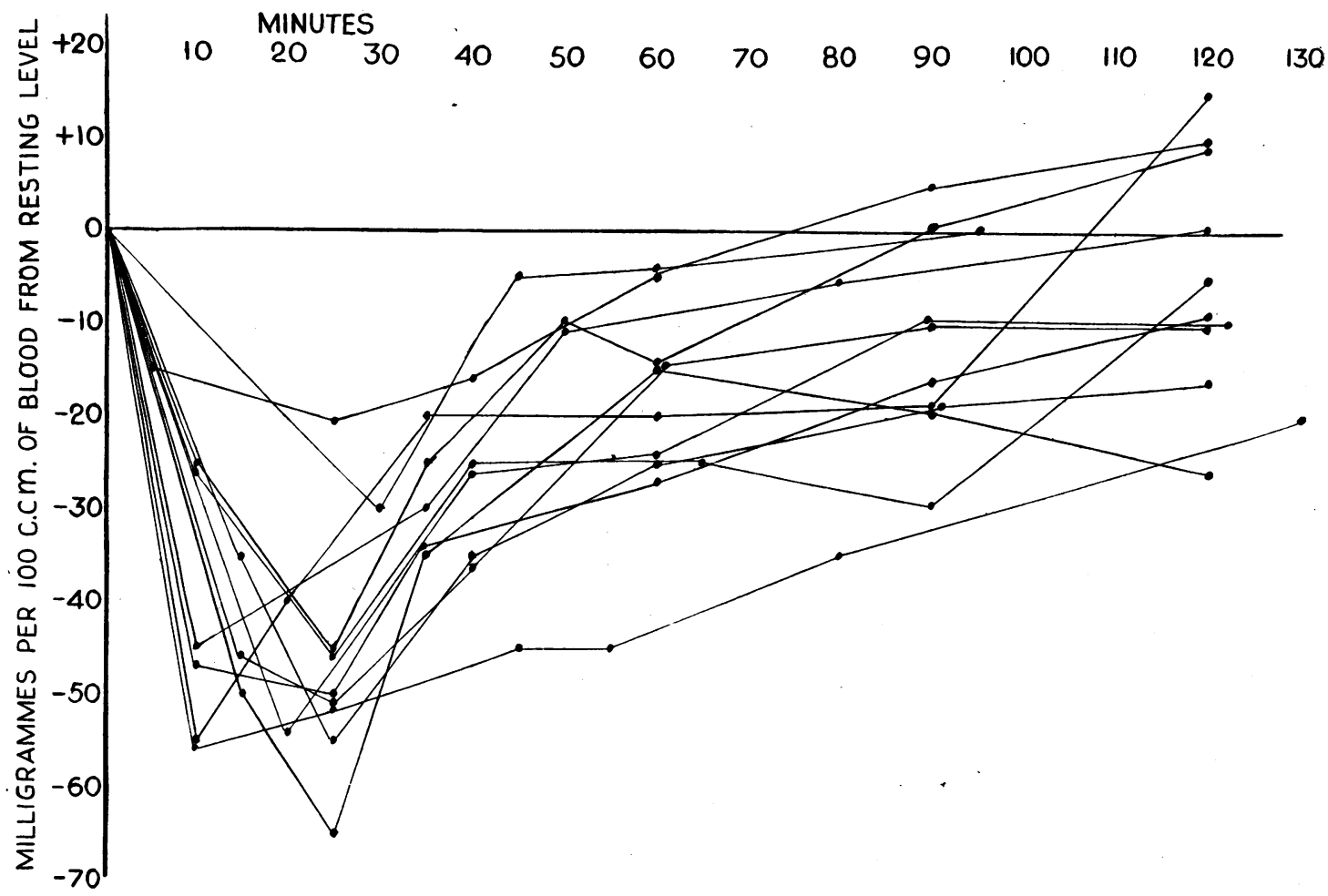

FIG. 2.-Normal intravenous insulin tolerance. 


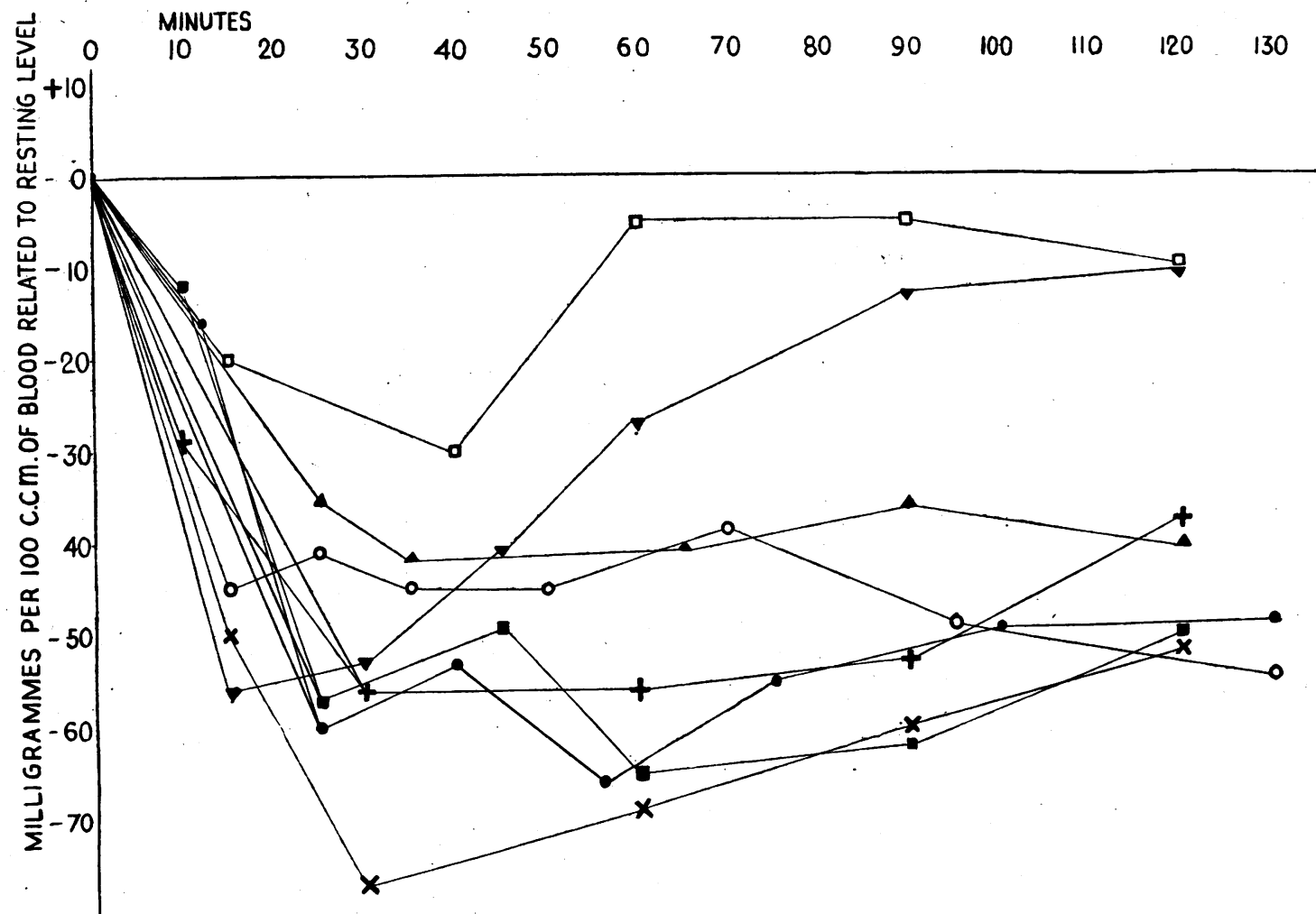

Fig. 3.-Insulin tolerance: 'coeliac.

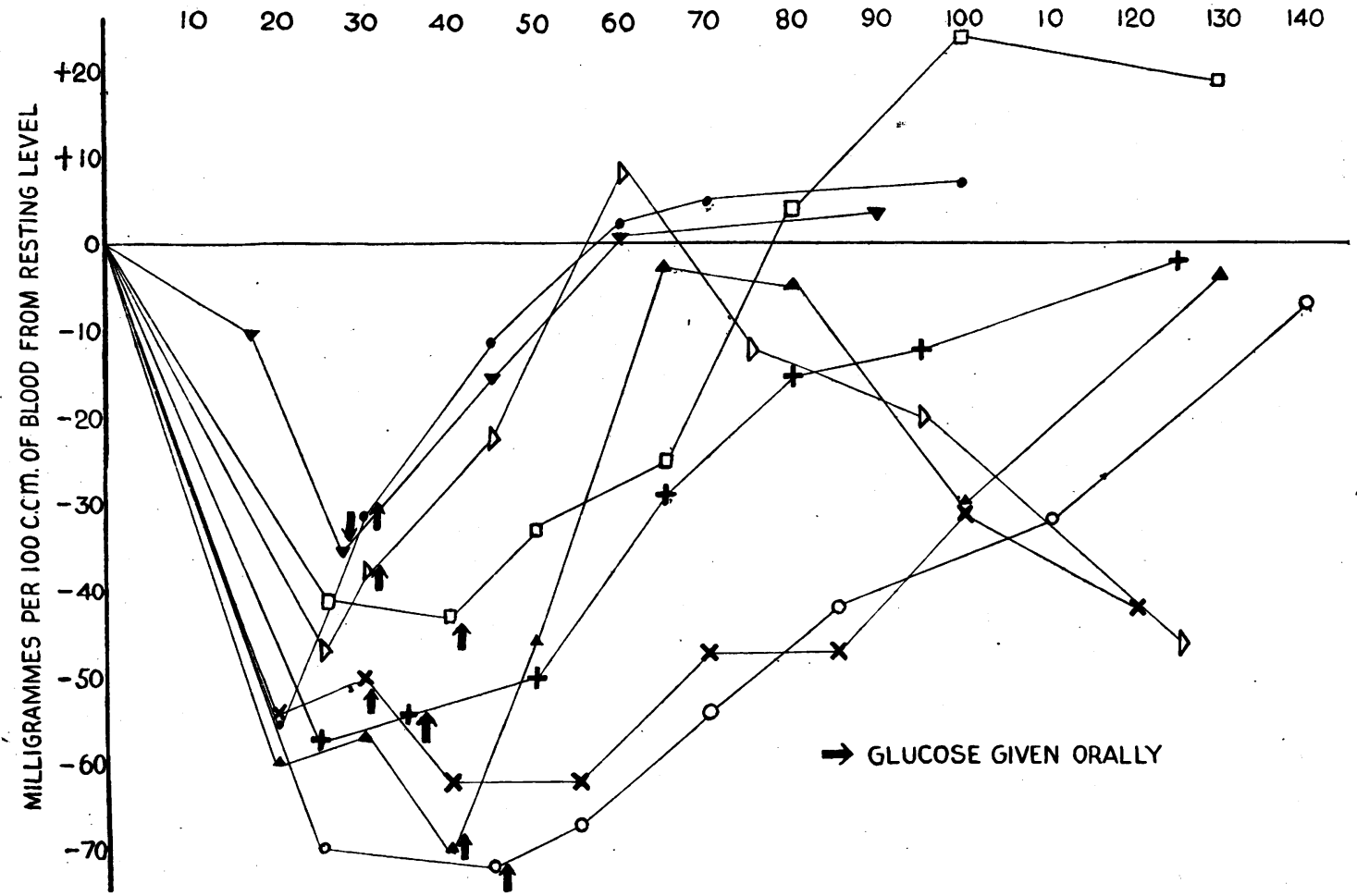

Fig. 4.-Intravenous insulin followed by oral glucose. 


\section{Resilts}

Oral ghecose tolerance. (Fig. 1.) It was seen that the majority of curves showed no appreciable rise in blood sugar. The purpose of reproducing some of the curves is to draw attention to specific features of form. In cases 1, 2, and 5, there occurs after the 60-minute period a definite depression of the blood-sugar level. This depression is seen in the 40- to 60-minute period in case 3. This period of depression, although not constant, can be seen in other reported cases, e.g. curves (b) and (c) in case 1 of Svensgaard. It is possible that this depression corresponds to the depression often noted at the end of a normal glucose-tolerance curve, due to a temporary overaction of the mechanism immobilizing glucose. It may be said with some justification that this degree of variation is within the limits of the normal variation in sugar level, errors in technique, and nervous reaction: but the latter usually shows itself by a raising of the blood-sugar level. The constancy of this period of depression is at least noteworthy. Thus in some cases of the coeliac syndrome the oral glucose tolerance curves show-a period of blood-sugar depression which may correspond to similar depressions in normal curves and indicate that the body is reacting as if glucose were absorbed.

Intravenous insulin tolerance. (Figs. 2 and 3.) The curves may be analysed in two parts: (a) the first 30 minutes, which includes the immediate glycolytic response to the injected insulin; and (b) the following 90 minutes, which demonstrate the reaction to the reduced blood sugar.

(a) THE FIRST 30 minutes.-It would be easy to miss a maximal peak in the fall of the blood sugar by taking specimens at 10 -minute intervals. For this reason the area, mg.-minute, depression of the first $\mathbf{3 0}$ minutes would give a more reliable criterion for comparison. In twelve control curves the mean volume was $950 \mathrm{mg}$.-minute (varying from 482 to 1,192). In twenty curves covering the same period in coeliac children the mean volume was $911 \mathrm{mg}$.-minute (varying from 495 to 1,397). It is considered that these figures, in association with the general similarity of the curves in their angle of fall, justify the conclusion that the immediate response to insulin as portrayed by a fall in blood sugar is normal.

(b) THE LATER 90 minutes.-Here there is a marked difference between 'coeliacs' and controls. At 50 minutes and subsequently all but one of the controls show a blood-sugar level within $30 \mathrm{mg}$. per $100 \mathrm{c} . \mathrm{cm}$. of blood below the fasting level, and by two hours they are fairly well grouped about the fasting level. In the 'coeliacs' two curves are within normal limits (cases 1 and 5). The remaining seven curves show what is termed 'hypoglycaemic unresponsiveness.' This phase does not show a completely uniform level, but most curves have an initial slight rise which is not maintained. The significance of this reaction is net easy to assess. However, in view of this apparently normal initial response (which was also observed by Crawford), it is thought that it is justifiable to discard the concept of failure of the pituitary-thyroid-adrenal mechanism, and to consider glycogen deficiency as the most likely explanation. This point requires further investigation, both in other types of marasmus and in cases of liver deficiency. Thus in 'coeliacs' the immediate reaction to intravenous insulin is normal, but there is, generally, an inability to regain the original blood-sugar level after hypoglycaemia produced by insulin.

Intravenous insulin followed by oral glucose. (Fig. 4.) The significance of these curves can best be assessed when compared with the other curves of the same patient, but the difference between figs. 3 and 4 is evident - in general the curves are transformed to normal insulin response curves. Case 11 is unique in that there is an immediate rise to above the resting level, followed by a steady fall, so that at 120 minutes the same level is reached as where no glucose is given orally. Case 2 (not included in fig. 4) showed a remarkable and rapid rise after a three-hour period of hypoglycaemia, thus suggesting the possibility that the longer the period of hypoglycaemia the more rapid the eventual absorption of glucose. Thus, in 'coeliacs,' glucose by mouth, in dosage insufficient to produce a rise in blood sugar when the latter is at resting level, produces a marked rise when the blood sugar has been lowered by insulin.

Adremaline after insulin. Four 'coeliacs' at the 120-minute periogd produced, with adrenaline, rises of $26,16,20$, and $18 \mathrm{mg}$. per $100 \mathrm{c} . \mathrm{cm}$. of blood respectively during the next $\mathbf{3 0}$ minutes. It did not seem justifiable to do control curves to cover this period. In two cases the adrenaline was given at a point corresponding to that at which glucose was given after insulin (fig. 5). The response is distinctly abnormal, there being a very small rise in blood sugar - and that not maintained. This same slight rise was noted in the simple insulindepression curves in these cases, and thus it seems that the adrenaline does not affect the nature of the curves. Thus in 'coeliacs' adrenaline fails to produce a normal response in the early hypoglycaemic phase after insulin, but adrenaline does produce some response two hours after insulin has been given. As the usual 'coeliac' curve is not 


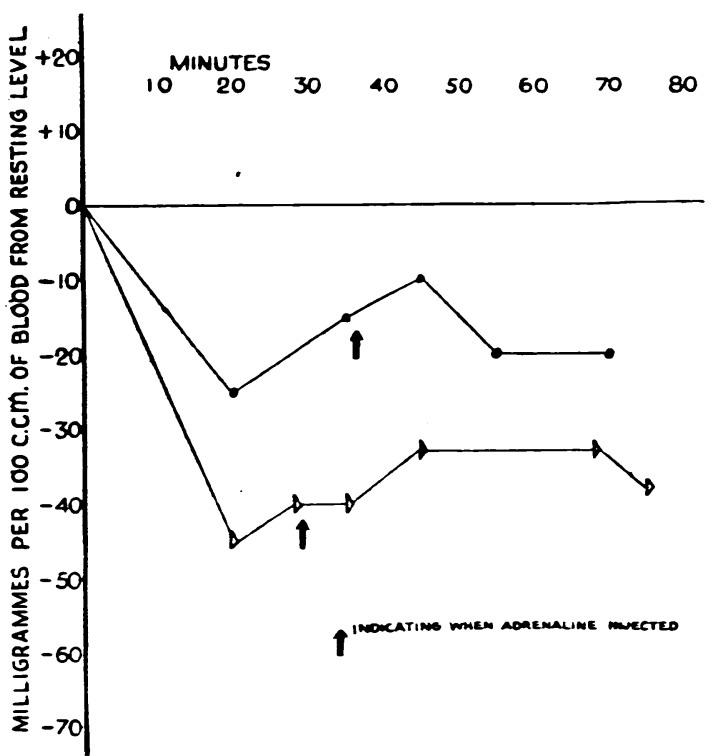

FIG. 5.-Intravenous insulin followed by adrenaline. altered by adrenaline, it would seem that the abnormality of the curve is not due to a lack of adrenaline.

Adrenaline response at normal fasting level. (Fig. 6.) In nine control cases the mean mg.-minute area for 60 minutes was 1,512 . In all, fifteen tests were performed on the 'coeliacs' (in three cases two curves were obtained); the mean mg.-minute area was 933. Inspection of the curves shows that they differ chiefly in the first 20 minutes, the rate of blood-sugar rise being slower in the test cases. Thus 'coeliacs' shòw a diminished glycaemic response to adrenaline in the fasting state. The rate of rise of the blood sugar following the injection of adrenaline is slower than normal.

Oral ghucose with intramuscular adrenaline. (Fig. 7.) Six 'coeliacs' and two controls were used. Although so few controls were employed, the curves appear to be within normal limits. It will be noted that in the first 20 minutes the graphs are remarkably similar. In the table the 60 minute areas of the curves obtained are analysed. It will be seen that in the 'coeliacs' the sum of the volumes of the separate oral glucose and adrenaline responses is far short of the volume obtained when adrenaline is combined with the oral glucose. This does not occur with the controls. Thus in
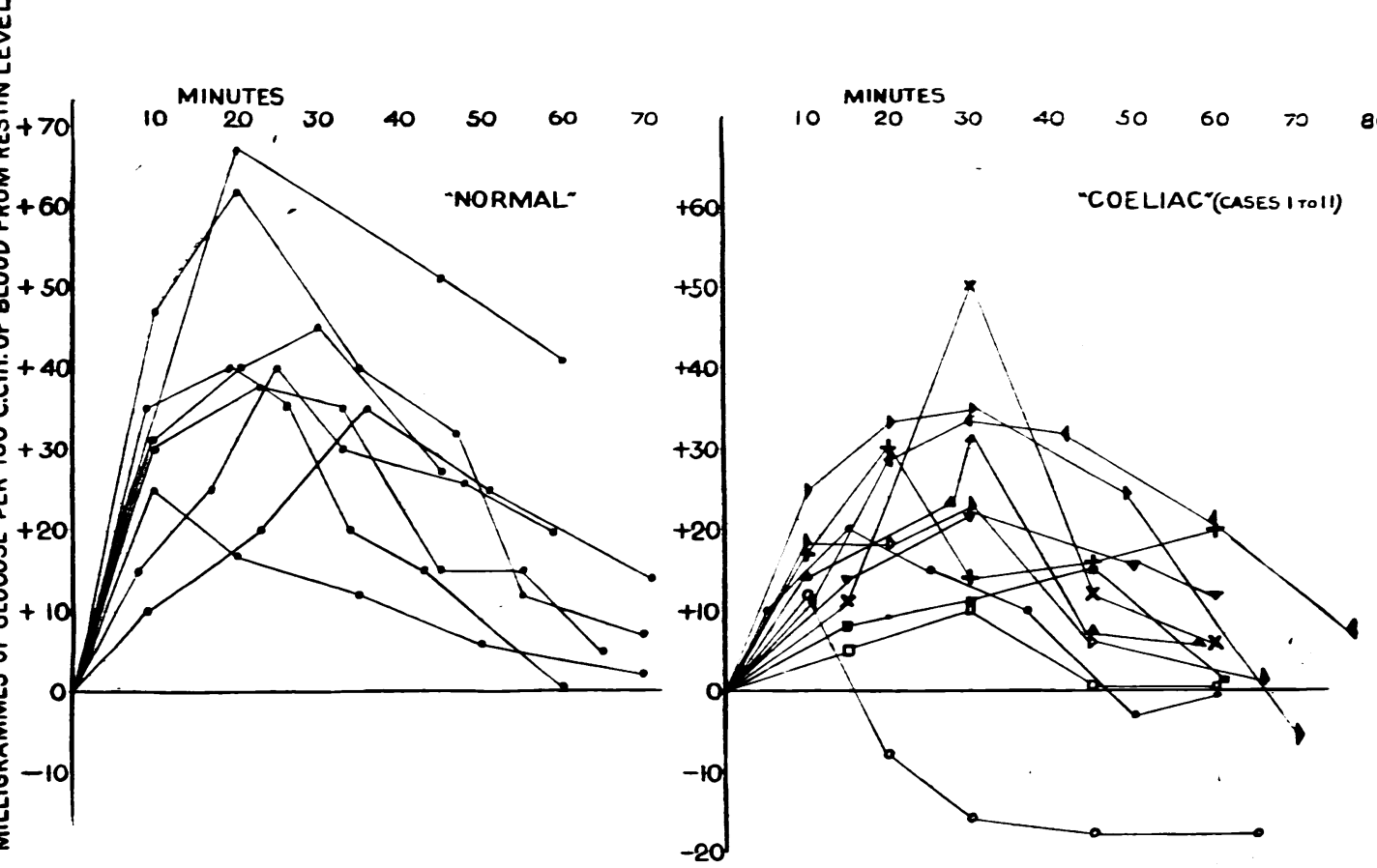

Fig. 6.-Intramuscular adrenaline response. 


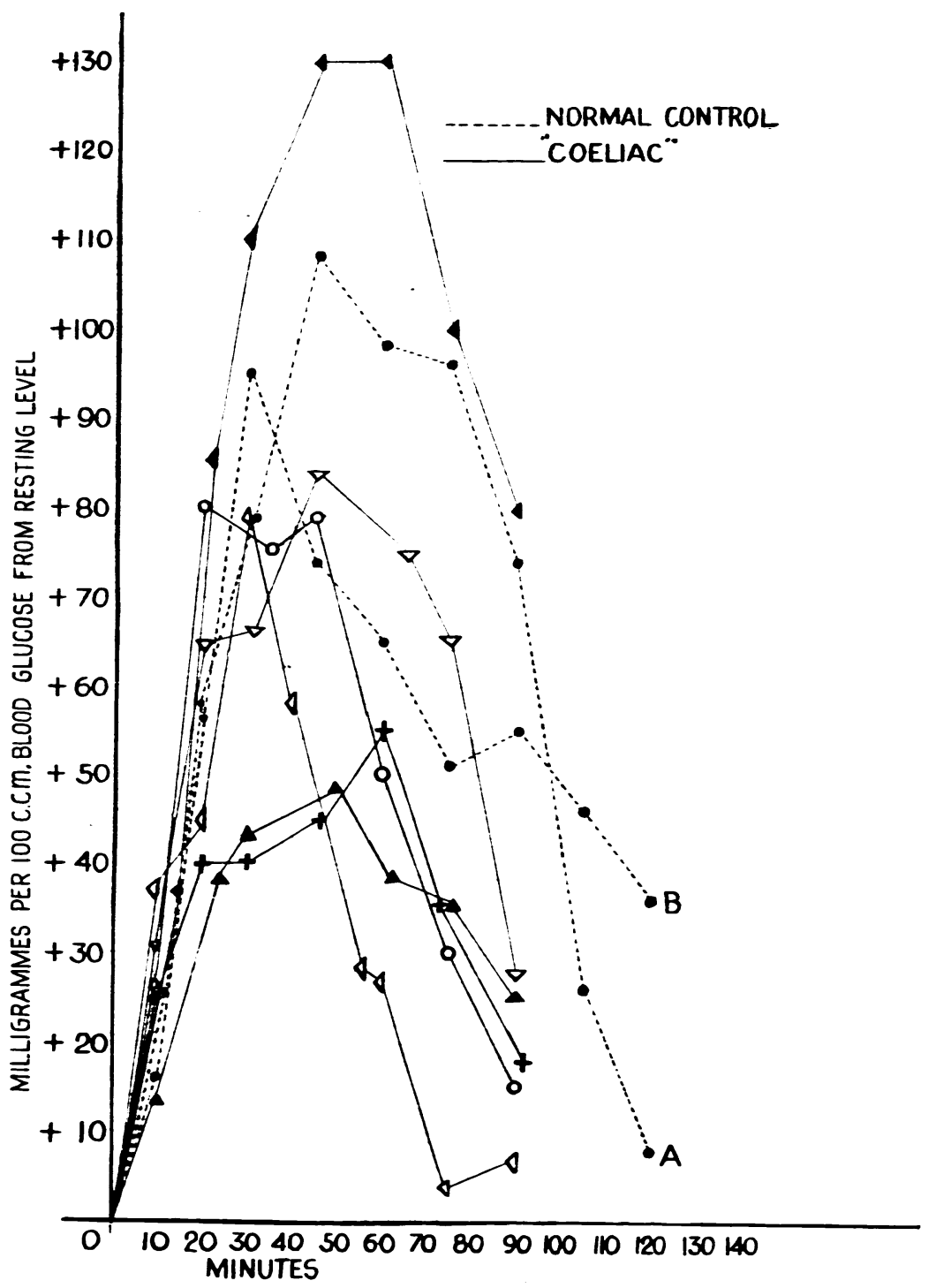

Fig. 7.-Combined test. Oral glucose and intramuscular adrenaline.

'coeliacs' the rise in blood sugar following the combined administration of oral glucose with intramuscular adrenaline is within normal limits. The response to the combined administration of oral glucose and parenteral adrenaline greatly exceeds the sum of the separate responses.

Intravenous ghucose tolerance. (Fig. 8.) The curves obtained in the 'coeliacs' and controls are cesentially the same (as was found by Crawford):
The curve from case 11 is included, as it is the only one approximating to those of Ross. It was obtained in unusual circumstances. At the time of the test the child, with a staphylococcal infection, was within a few hours of death and the glucose was administered through a transfusion apparatus that had previously been set up.

Thus intravenous glucose tolerance in 'coeliacs' is within normal limits. Tolerance may be impaired during an infection. 
TABLE SHOWING THE RELATIONSHIP OF THE VOLUMES OF THE CURVES OBTAINED WITH ORAL GLUCOSE AND WITH INTRAMUSCULAR ADRENALINE, AND IN THE COMBINED TEST. ALL FIGURES ARE MILLIGRAMME-MINUTE VOLUMES FOR 60 MINUTES.

\begin{tabular}{|c|c|c|c|c|c|}
\hline Coeliac & $\begin{array}{l}\text { Oral glucose } \\
\text { tolerance }\end{array}$ & $\begin{array}{c}\text { Adrenaline } \\
\text { tolerance }\end{array}$ & $\begin{array}{l}\text { The sum of oral glu- } \\
\text { cose tolerance }+ \\
\text { adrenaline tolerance }\end{array}$ & $\begin{array}{l}\text { Combined test-oral } \\
\text { glucose with adrena- } \\
\text { line }\end{array}$ & Difference \\
\hline $\begin{array}{l}\text { A.Z. } \cdots \\
\text { B.Y. } \cdots \\
\text { H.W... } \\
\text { D.T. } \cdots \\
\text { E.S. } \quad \cdots \\
\text { K.P. } \cdots\end{array}$ & $\begin{array}{r}354 \\
280 \\
1,477 \\
822 \\
-320 \\
785\end{array}$ & $\begin{array}{r}875 \\
902 \\
1,443 \\
715 \\
1,035 \\
2,355\end{array}$ & $\begin{array}{r}1,229 \\
1,182 \\
2,920 \\
1,537 \\
715 \\
3,140\end{array}$ & $\begin{array}{l}3,415 \\
2,234 \\
5,286 \\
2,242 \\
1,952 \\
3,592\end{array}$ & $\begin{array}{l}+2,186 \\
+1,052 \\
+2,366 \\
+\quad 705 \\
+1,237 \\
+\quad 452\end{array}$ \\
\hline \multicolumn{6}{|l|}{ CONTROL: } \\
\hline $\begin{array}{l}\text { L.G. . } \\
\text { M.J. . }\end{array}$ & $\begin{array}{r}787 \\
3,150\end{array}$ & $\begin{array}{l}2,700 \\
1,817\end{array}$ & $\begin{array}{l}3,487 \\
4,967\end{array}$ & $\begin{array}{l}3,560 \\
3,620\end{array}$ & $\begin{array}{l}+73 \\
-1,347\end{array}$ \\
\hline
\end{tabular}

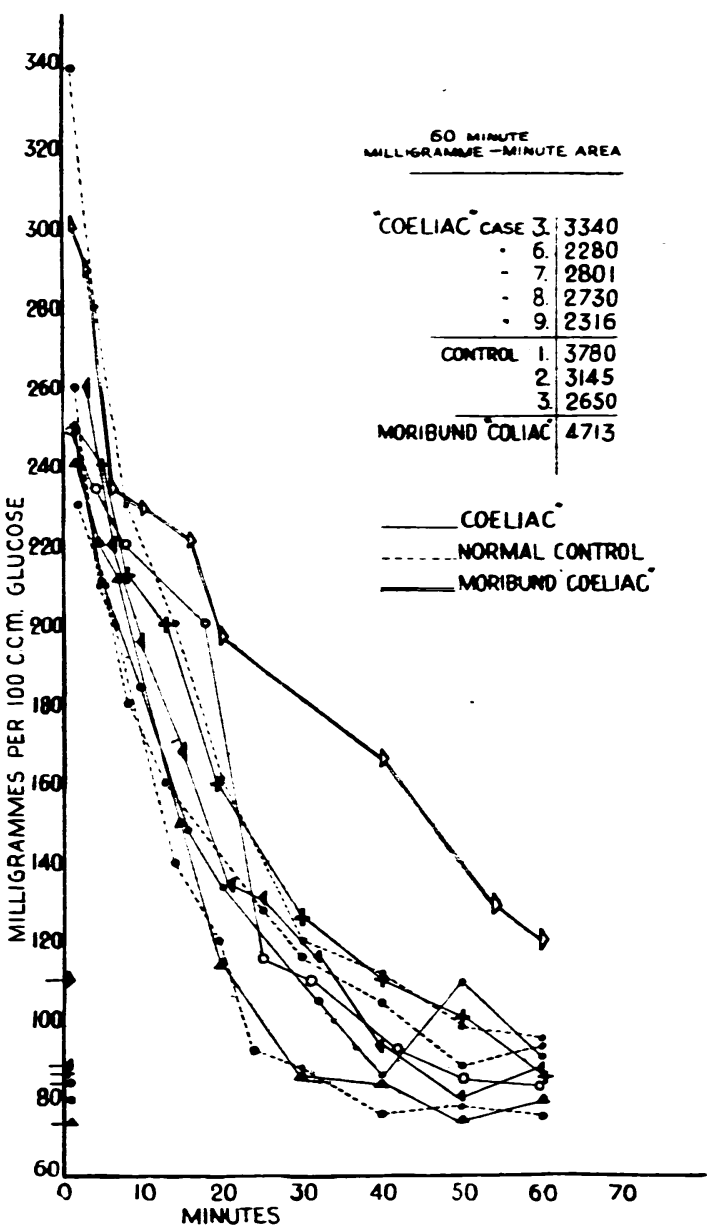

Fig. 8.-Intravenous glucose tolerance.

\section{Discussion}

It is difficult to see any other reasonable explanation of the response to oral glucose after insulin than that, in 'coeliacs,' glucose is absorbed. Similarly, judging from the normal response to the combined adrenaline and oral glucose, it appears to be absorbed at the normal rate.

If it is accepted that glucose absorption is normal, the flat oral glucose-tolerance curve indicates a more rapid fixation of glucose. The finding of normal intravenous glucose tolerance at first sight seems to contradict this; but there are two other factors to be considered: (a) to produce a rise in peripheral blood sugar the absorbed glucose must first have passed through the liver; (b) all observers agree that a normal oral glucose-tolerance curve is obtained in 'coeliacs' if a large dose of glucose is given. Thus it is only legitimate to relate directly oral and intravenous glucose tolerance if the liver is functioning normally as regards glucose, or even more correctly when the liver tends to let glucose through (diabetes mellitus is the disorder in which these tests have been most used). It is reasonable to suppose that if the liver is deficient in glycogen it would immediately take up a small quantity of glucose. Mirsky and Nelson (1944) showed that the normal immediate liver glucose reserve in a child lies between 15 and $20 \mathrm{~g}$. If in 'coeliacs' the reserve is lacking, a quantity of glucose in the region of $10 \mathrm{~g}$. reaching the liver via the portal vein would be immediately fixed. This is the quantity of glucose given in the present series of investigations. Larger doses would be expected to produce a rise in the peripheral blood sugar only.

A deficiency of liver glycogen is also the most reasonable explanation for the failure of the blood 
sugar to regain its original level after intravenous insulin; the small immediate rise seen may be due to a small quantity deposited as glycogen by the insulin.

The adrenaline responses are more obscure. In intact animals, Cori (1931) noted no increase in the A.V. blood-sugar difference after the administration of adrenaline; and Bridge and Noltie (1935) observed that, after intravenous injection of adrenaline, the respiratory quotient fell to the fatprotein level. (Himsworth and Scott (1938), using rabbits with excluded livers, obtained different results.) The adrenaline response in 'coeliacs' is smaller than normal, but, if the glycogen stores of the body are as low as we suspect, it is surprising that the response is as great as it is. The difference between the responses with adrenaline alone, and with oral glucose and adrenaline, indicates that in these cases adrenaline virtually prevents the immediate demobilization of glucose. The delayed response to adrenaline in these cases could well be due to a lack of immediately available glycogen for glycogenolysis, while the general response is possibly due to glucose produced from fat and/or protein, with possible failure of utilization. At this point in these investigations it would be premature to relate adrenaline directly to the etiology of the coeliac syndrome; but the observations of Hill and Koehler (1932) that the administration of adrenaline to rats produced an increase of 100 per cent. in faecal lipid excretion may be relevant here.

\section{Summary}

The findings in the coeliac syndrome may be summarized as follows:

1. Oral glucose-tolerance curves are flat, and, in addition, may show periods of actual fall in bloodsugar level.

2. The immediate fall in blood sugar due to insulin is normal. There is usually a failure of the blood sugar to regain its original level in the normal time, although after the original fall there is often a temporary rise.

3. The relative failure of the blood sugar to rise after administration of insulin is not affected by adrenaline: this suggests that there is no deficiency of that substance.

4. Oral glucose, when the blood sugar is low after insulin, does restore the blood sugar to normal.

5. Adrenaline, when not preceded by insulin, produces a rise in blood sugar which is less than the normal. This difference is most noticeable in the early period, when the rise is less rapid.
6. When oral glucose is given at the same time as adrenaline there is an immediate and rapid rise in blood-sugar level-as in normal subjects.

7. Intravenous glucose is removed from the peripheral blood stream at a normal rate.

Direct and indirect evidence has been produced to show that children in the 'coeliac' state can absorb glucose normally, can also utilize it normally, but lack available glucose. Thus the carbohydrate metabolism in these children appears to correspond with that in other marasmic states, as demonstrated by Fleming and Hutchison (1924), and by Tisdall et al. (1925).

Thanks are due to the Honorary Staff of the Bristol Children's Hospital for allowing the investigations upon their patients, and also to Prof. T. F. Hewer, Dr. Beryl Corner, and Dr. J. Apley for criticism of the manuscript. In particular I would like to thank Prof. C. Bruce Perry for his guidance and for the interest he has taken in this investigation.

\section{REFERENCES}

Andersen, D. H. (1945). Amer. J. Dis. Child., 69, 141. $\longrightarrow$, and Early, M. V. (1942). Ibid., 63, 891.

Badenoch, E., and Morris, N. (1936). Quart. J. Med., 5,227

Bridge, E. M., and Noltie, H. R. (1935). J. Physiol., 85, 334.

Cori, C. F. (1931). Physiol. Rev., 11, 143.

Crawford, T. (1939). Quart. J. Med., 8, 251.

Fleming, G. B., and Hutchison, H. S. (1924). Ibid., 17, 339.

Fraser, R. W., Albright, F., and Smith, P. H. (1941). J. clin. Endocrinol., 1, 297.

Hill, E., and Koehler, A. E. (1932). J. biol. Chem., 98, 185.

Himsworth, H. P., and Scott, D. B. M. (1938). J. Physiol., 93, 159.

MacLean, A. B., and Sullivan, R. C. (1929). Amer. J. Dis. Child., 37, 1146; 38, 16.

Mirsky, I. A., and Nelson, W. E. (1944). Ibid., 67, 100.

Parsons, L. G. (1932). Ibid., 43, 1,293.

Ross, C. W., and Tonks, E. L. (1938). Arch. Dis. Childh., $13,289$. (1936). Lancet, 2, 556.

Rudeshill, C. L., and Henderson, R. A. (1941). Amer. J. Dis. Child., 61, 108.

Svensgaard, E. (1931). Acta paedriatr. Stockh., $12,1$.

Thaysen, T. E. H. (1929). Lancet, 1, $1,086$.

(1935). Quart. J. Med., 4, 359. 17.

_ 1929. Ibid., 44, 477.

Tisdall, F. F., Drake, T. G. H., and Brown, A. (1925). Amer. J. Dis. Child., 30, 829. 